\title{
An Investigation into Social Learning Activities by Practitioners in Open Educational Practices
}
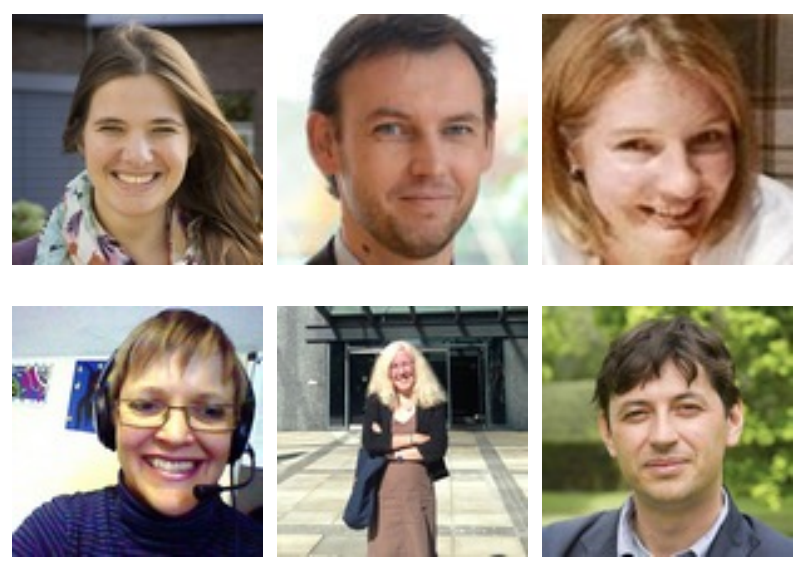

Bieke Schreurs ${ }^{1}$, Antoine Van den Beemt ${ }^{1}$, Fleur Prinsen ${ }^{1}$, Gabi Witthaus ${ }^{2}$, Gráinne Conole ${ }^{2}$, and Maarten De Laat ${ }^{1}$

1Open Universiteit Nederland, 2University of Leicester, UK

\section{Abstract}

By investigating how educational practitioners participate in activities around open educational practices (OEP), this paper aims at contributing to an understanding of open practices and how these practitioners learn to use OEP. Our research is guided by the following hypothesis: Different social configurations support a variety of social learning activities. The social configuration of OEPs is investigated by an operationalization into the dimensions (1) practice, (2) domain, (3) collective identity, and (4) organization. The results show how practitioners of six different OEPs learn, while acting and collaborating through a combination of offline and online networks. The findings of our study lead to practical implications on how to support participation in OEP, and thereby stimulate learning in (online) networks of OEP.

Keywords: Open educational practices; networked learning; communities of practice 


\section{Introduction}

Researchers claim that the success and sustainability of open educational practices (OEP) depend on prospering and fit OEP movements built around full and open collaboration between educational institutions and amongst individual practitioners (Lane, 2008). However, little insight exists into how these groups of practitioners come to live, function, or learn together with colleagues (Fetter, Berlanga, \& Sloep, 2011). To improve our understanding of open practices and how practitioners involved in OEP initiatives learn to use OEP, this article investigates how these practitioners participate in a range of activities around OEP such as the creation, adaptation, and reuse of OEP and accreditation of OEP-based learning.

Our work is empirically supported by the findings from six case studies into communities based on OEP. These results contribute to an understanding of how practitioners learn within these six different OEP while acting and collaborating mostly, but not entirely, through online networks. In more detail, we investigate the social configuration of these six OEP and investigate how this social configuration influences the learning of practitioners. The findings of our study lead to practical implications on how to support participation in OEP, and thereby stimulate learning in (online) networks of OEP.

\section{Theoretical Background}

In this article, we perceive lifelong learning as participation-based and situated in shared work practices. On the one hand, this perspective is rooted in the idea of communities of practice (CoPs) (Lave \& Wenger, 1991). On the other hand, we discuss how recent organizational developments, such as new ways of working and the use of social media in organizations, could change the organizational landscape, engendering open networks in which practitioners work, learn, and innovate. In this article we focus on the way learning is taking place through participation in such open practices. We are specifically interested in understanding how social participation and collaboration is taking place.

In practice we see many different forms of social collaboration unfold, especially since people come and go based on their changing needs. This group dynamic results in diversity in strength of relationships between participants and thus leads to diversity in presence and engagement in group learning (Dron \& Anderson, 2007). To understand the nature of these open practices different typologies of social forms that a collection of learners might participate in have been developed (Dron \& Anderson, 2014). In what follows we distinguish between communities, networks, and teams and use these concepts to explore learning embedded in OEPs. 


\section{Communities of Practice}

In recent years, we have witnessed an uptake of OEPs in many countries (for a list of more than 124 notable OEP initiatives, please see http:// poerup.referata.com/ wiki/ Country_reports). Researchers investigating professionals who collaboratively participate in these initiatives often refer to the concept of 'communities of practice' (CoPs): groups of people who share a craft and/or profession (Lave \& Wenger, 1991). Participants in a CoP are informally bound by what they do together and by what they have learned through their mutual engagement in these activities (Wenger, 1998). However, it is argued that the informal binding of individuals based on shared interests may be non-committal and may not contribute directly to learning activities (Büchel \& Raub, 2002). Commitment can be established when the shared activities of a group are embedded in a historical and social context that gives structure and meaning to these activities.

Based on the work of Wenger (1998), a large number of studies show how professionals organize their lives together with colleagues, peers, and customers in CoPs to get their jobs done. These studies also show how within communities the rules of the working game are set: how to do the job and how to do it more efficiently. If these rules about performing a practice are the core business of a CoP, one might expect however that members of a $\mathrm{CoP}$ would be reluctant to change the way things are done in the group, or the practice they work in. Much of the research and practice around CoPs has focused on establishing the core of these communities and developing skills and competencies to participate in them (Admiraal, Lockhorst, \& Van der Pol, 2012). While the focus has been on community building efforts, the important notions of Wenger (1998) on boundary crossing and the ability of CoPs to constantly negotiate their practices have been largely ignored.

\section{Networks of Practice}

Today, practitioners increasingly realize that opportunities for growth, development, and innovation lie outside their own organization. These and recent other technological developments have given rise to more openness in organizational practices. This openness makes employees less constrained by boundaries that otherwise would impede knowledge sharing. Current technologies and use of social media for example enable professionals to connect with their peers with greater ease, at a larger scale and on a continuing basis (De Laat, Schreurs, \& Nijland, 2014). By emphasizing for instance relationships and flows of information, networks of practice are distinguished from CoPs (Wenger, Trayner, \& De Laat, 2011; Brown \& Duguid, 2001). Others define networks of practice as 'nets', resulting from individual connections between people, with no explicit hierarchies or membership (Dron \&Anderson, 2014).

Bottrup (2006) speaks of the potential of network-based learning as an important complement to workplace learning and formal learning. She claims that networks could be a special arena for learning because they give professionals the potential to take a 
needed step away from their daily work practice to reflect and search for new perspectives amongst peers. At the same time network members share goals, which could make it easier to translate shared knowledge to their own working environment.

Open networks of practice are "collections of individuals who come together across organizational, spatial and disciplinary boundaries to create and share a body of knowledge" (Pugh \& Prusak, 2013). These networks have shifting and distinct boundaries (Dron \& Anderson, 2014). The focus of such networks is usually on developing, distributing, and applying knowledge and, to some extent, on building a collective identity as is seen in communities. Organizations of all sizes are seizing this model to learn more quickly and collaborate productively (Pugh \& Prusak, 2013).

\section{Teams}

Alongside communities and networks, 'teams' can be found: 'groups of people that work together cohesively toward a common goal' (Dechant, Marsick, \& Kasl, 1993, p. 1), where members have been assigned specific roles or functions to perform' (Salas, Dickinson, Converse, \& Tannenbaum, 1992). This description resembles Dron and Anderson's (2014) definition of 'groups': externally regulated entities, with clear goals, attributes, and rules. Team learning is defined by tasks rather than knowledge and often guided by institutional schedules and limitations in authorized groups. In contrast, a community's life cycle is determined by tacit knowledge sharing in informal groups based on self-organization and volunteered participation with boundaries beyond the organization (Knapp, 2010). A community can be located somewhere between teams and networks as a form of social organization (Wenger, Trayner, \& De Laat, 2011).

\section{Learning in Social Configurations}

Our perspective on learning follows Boud and Hager (2012). They emphasize learning as a continuous process driven by needs that emerge in daily practice, by using terms such as organic growth, evolution, and gradual unfolding. Learning is a process of participation in practice, where professionals continuously develop their identity and abilities in response to events in their professional environment. Boud and Hager thus place learning in a social context, where professionals work and learn together, change and innovate both their professional practice as well as who they are. This perspective on learning involves being in touch with professional colleagues, building the networked connections needed to participate in constructive professional dialogues about what it means to become a professional, and being able to perform in the workplace (Lohman, 2006). Learning in a social context requires facilitation (Büchel \& Raub, 2002) and a safe supporting environment (Dron \& Anderson, 2014). To implement OEPs, developing, sharing, and applying knowledge are of undeniable importance (Lane, 2008). However, how do practitioners learn from each other while involved in OEPs? Do OEPs encourage the emergence of more or less 'pure' communities, networks, or teams? Can we distinguish different social configurations and, if so, how does the social configuration influence the way practitioners learn from each other to implement OEPs? 
We argue that these social configurations within OEPs can influence the learning activities.

Although the complexity of social learning has been acknowleged and theoretically explained little is done to help identify this in practice. Most of this work is done from a single theoretical construct, be it community, networks, or teams. For example, Galley, Conole, and Alevizou (2012) develop community indicators to observe and support online communities. Admiraal, Lockhorst, and van der Pol (2012) developed a community support framework to help develop teacher communities.

But in practice, social learning is a palette of colors that blends in different ways (Dron \&Anderson, 2014). The study of the complexity of social learning cannot be restricted to a strict theoretical typology (Wenger, Trayner, \& De Laat, 2011). Therefore Vrieling, Van den Beemt, and De Laat (in press) developed a framework that perceives the characteristics of communities, networks of practice, and teams as integral aspects of social learning.

\section{Dimensions of Social Configuration}

The framework of Vrieling, Van den Beemt, and De Laat (in press) operationalizes the social configuration of OEPs into four dimensions: (1) practice, (2) domain, (3) collective identity, and (4) organization. Each of the four dimensions is constructed from several indicators, which reflect leading themes in literature on social learning. These indicators are measured as the extent to which the group shows specific attitudes and behaviour. The dimension practice refers to the extent to which the group knowledge is integrated into day-to-day activities and the extent to which the group shows continuous rather than temporary activities. Domain refers to the shared area that inspires the participants to share, broaden, or deepen their knowledge and skills within the group. This sharing can lead to value creation on the individual, community, and society levels, provided the group has a clear purpose and goals (see also Büchel \& Raub, 2002). Collective identity measures the mutual engagement that binds the members together in a social entity, shown for instance by strong ties and the perception of group members as knowledge workers. This mutual engagement goes together with feelings of openness and trust among the participants (Van den Beemt, Ketelaar, Diepstraten, \& De Laat, 2014). Organization refers to the extent to which the group members have a shared interactional repertoire, a focus on local or global activities, and equal or hierarchical power relations. Furthermore indicators in this dimension refer to the extent to which the group is self-organized and has influence over its own goals, tasks, and methods (Bottrup, 2006), rather than being directed by management. This indicator should not be confused with management support, which is considered an important organizing premise for successful group learning (Büchel \& Raub, 2002).

In order to complete the framework guiding our investigation, we included questions referring to the indicators 'sustainability' and 'creative ability' based on the framework 
of Galley, et al. (2012). Galley and colleagues (2012) see persistence of activity as a crude indicator of successful social learning. In their view, a group is successful when the activity continues until the problem is solved. Another important factor according to the authors is creative ability. Creative ability refers to the competences needed to create shared artefacts, shared knowledge, and understanding. This could be particularly important in networks of practice, where people cross institutional borders and work with relative strangers (Galley, et al., 2012). We believe that with this framework we are able to describe a diversity of social configurations.

\section{Main Hypothesis}

We argue that the dimensions of domain, practice, collective identity, and organization can add to an understanding of the functionality of social learning in the field of OEPs. Starting from these dimensions, our main hypothesis is that different social configurations support a variety of social learning activities. We provide preliminary evidence for this hypothesis with reference to empirical data from the six case studies on OEPs.

\section{Methodology}

\section{Sampling}

From an inventory of 124 OEP initiatives worldwide, compiled by the POERUP project (http:// www.poerup.info/), six case studies were selected. The case studies are defined as notable OEP initiatives. OEP was defined as a set of activities and support around the creation, use, and repurposing of open educational resources (OERs) and MOOCs.

Selection criteria for the cases were: inclusion of primary, secondary, higher education, and vocational training, both long-standing and new initiatives, easy access to respondents through partner contacts, and both national and international initiatives.

\section{Selected Cases}

1. Digischool, a national initiative in the Netherlands, started by two teachers in 1995 and resulted in a collection of virtual schools where primary and secondary teachers can share open learning materials and discuss the use of open learning materials in virtual communities. Seventy teachers manage the virtual communities. (http:// www.digischool.nl/)

2. UvAMOOC: The first MOOC (massive open online course) in the Netherlands, titled "Introduction to Communication Science" is an initiative of the University of Amsterdam's College of Communication and the Graduate School of Communication 
Science. It has been run since 2013. The target group consists of college students and lifelong learners all over the world. (http:// mooc.uva.nl/portal)

3. The OERu (OER universitas) is an international initiative of the Open Educational Resource Foundation, based in New Zealand, set up in 2011, with the aim of widening participation in higher education by accrediting OER-based learning. The OERu is a consortium of over 30 public post-secondary institutions. Alongside the consortium, the OERu is enhanced by a system of volunteers (Mackintosh, McGreal, \& Taylor, 2011). (http:// oeru.org/ and http:// wikieducator.org/OERu/Home)

4. The Canadian initiative BCcampus, established in 2002 by the provincial government of British Colombia, is a publicly funded organization that aims to bring people from British Colombia's post-secondary system together and make higher education available to everyone by collaborative information technology services. Within this study, we investigated the open education subgroup of the BCcampus project. (http:// bccampus.ca/)

5. FutureLearn is a private company fully owned by the UK Open University (FutureLearn, 2013). It has collaborated with over 20 leading UK and a few non-UK universities and cultural institutions to form the FutureLearn consortium. Since October 2013, the consortium has offered a range of MOOCs at university level

6. Re:Source is an initiative of the Scottish Further Education Unit aimed at developing OER for Scotland's colleges. The initial development work took place during 2012 and it is currently managed by the (Scotland) College Development Network. (http:// resource.blogs.scotcol.ac.uk/)

\section{Data Collection Method}

For each case study, three in-depth structured interviews were conducted, resulting in 18 interviews. Interviews were held with an academic contributor representing an institutional partner, a coordinator or manager, and a person responsible for the technical support or a volunteer. This selection was aimed at including both support staff and academic staff and peripheral participants. The interview scheme was guided by the four superordinate dimensions: (1) domain, (2) practice, (3) collective identity, and (4) organization (Vrieling, Van den Beemt, \& De Laat, in press). For the OEP context, we adapted the framework by combining it with the community indicator framework consisting of the dimensions participation, cohesion, identity, and creative capability (Galley, Conole, \& Alevizou, 2012). The community indicator framework enabled us to include questions regarding facilities, support, and sustainability. The resulting framework was used to investigate and understand the social configuration of the networks the practitioners are engaged in. 
Table 1

Dimensions and their Indicators of Social Learning

\section{Practice}

1a. To what extent does the group exhibit integrated or non-integrated group activities in daily work?

$1 \mathrm{~b}$. To what extent does the group exhibit temporarily or permanent social activities?

2. Domain

2a. To what extent does the group focus on sharing or broadening/ deepening knowledge and skills?

$2 \mathrm{~b}$. To what extent does the group experience value creation, individually or collectively?

3. Collective identity:

3a. To what extent do participants exhibit a shared or unshared identity?

3b. To what extent does the group exhibit weak or strong ties?

3c. To what extent do the participants view one another as task executors or knowledge workers?

4. Organization:

4a. To what extent does the group operate externally directed or self-organized?

$4 \mathrm{~b}$. To what extent does the group exhibit local' or 'global' activities?

4c. To what extent does the group exhibit hierarchic of equal relationships?

$4 \mathrm{~d}$. To what extent does the group exhibit shared or non-shared interactional norms?

5. Facilities, support and sustainability

5.a What are the main communication technologies that you use for the activities you undertake as a community? (e.g., VLE, wiki, emails, Skype, etc.) Are these technologies easily available to you? If not, please can you describe the key barriers or obstacles. 5.b How do you rate the usability of the systems that <your community name> employs? (e.g., All systems usable, with internal evidence to back this up).

5.c How would you describe the levels of knowledge or skills demonstrated by the community members in the discussions, debates, and the collaborative productions? 5.d Is there nearby, fast response technical support available for the activities you undertake as a community?

5.e How do you perceive the sustainability of the community you are participating in (in terms of durability, ongoing costs, etc).

\section{Data Analysis}

All interviews were conducted in-person, in some cases via Skype, audio recorded, and lasted on average 45 minutes. The interviews were analysed using a coding scheme developed to generate insights within the four superordinate dimensions. Strategies for monitoring and improving intercoder agreement were used in the analytic process to maintain rigor.

The data analysis consisted of a within-case analysis to reach data reduction, followed by a cross-case analysis to search for patterns in the respondents' answers. In the first phase, data of each respondent were analysed. After coding of the interviews, a thematic coding around categories corresponding to the research question was performed. 
Finally, a comparative analysis of all respondents took place, which resulted in accounts to draw conclusions and verify the data with the theoretical concepts related to our research question.

The technique of 'constant comparative analysis' (Glaser \& Strauss, 2009) was used for both the vertical and the horizontal analysis in order to continuously compare preliminary interpretations with accounts of the other respondents and the theoretical framework.

\section{Results}

In what follows, we present how the four dimensions domain, practice, collective identity, and organization constitute the social configurations. Results are illustrated with data from the interviews. Subsequently we explore how the social configuration influences social learning activities.

\section{A) Shared Domain}

In all OEPs, educational staff showed dedication to, and could familiarize themselves with, a shared domain: to create and conduct OEPs. In some cases respondents felt they were partly responsible for developing or contributing to this shared domain, whereas in other cases it appeared they were rather 'executing' within a given shared domain. In this respect, the practices of some case studies can be labelled instrumental, such as FutureLearn, Digischool, and UvAMOOC, as they focus on producing OEP. Other case studies, such as OERu, BCcampus, and Re:Source, were found to be more supportdriven in their effort to create awareness about OEPs and enable partner institutions to produce and use OER and carry out OEPs.

All initiatives focus to some extent on creating a technological platform for sharing materials. Most initiatives use openly available media in combination with other platforms (e.g., Moodle). For example, within BCcampus the approach is to build on current uses of technology in order to include more people: "We try to be flexible and use what they feel comfortable with. We might set up a website or a wiki if we feel the people in the project feel comfortable with [that]."

Evaluation of OEPs was done in some form in all examined cases; in one case, this was done in an interactive fashion (quality tagging), and in another this was done through implementation of a centralized procedure (course evaluation). While in the OERu quality control has been part of their practices from the beginning, other initiatives struggle to get quality control in place.

Within the shared domain found in all case studies, each case has its own specific purpose. For example, OERu has the purpose of accreditation of OER-based learning, while BCcampus consists of many different working groups with topics ranging from 
open textbooks to educational technology support. The purpose of the UvAMOOC is to experiment with MOOCs as a form of teaching, and building up expertise around the use of instructional and technological design. The Re:Source case study focuses on sharing resources amongst different institutions to avoid duplication of materials, which involves a process of collaboration between several institutions.

All examined initiatives were set up to stimulate or exploit the use of technology within education in general, and the experiences and expertise gained within the projects are used to set political agendas. Therefore, they play an important role at the national policy level by pushing the political agenda of their region or country. In order to do so most but not all initiatives have close relations with national or regional policy advisors or ministries of education.

\section{B) Shared Practice}

The dimension shared practice is represented by the extent to which the group exhibits activities integrated in their daily work and the extent to which these activities are continuous.

OEPs that can be characterized by a support-driven approach, with a focus on creating and sharing knowledge, show a profound shared practice. For example the open textbook initiative as part of BCcampus saw librarians from different institutions working together on knowledge about open textbooks, copyright issues, and sustainability of educational materials. Other initiatives with a focus on creating and sharing materials, characterized as the instrumental approach, show a less profound shared practice. The case of Digischool consists of specific topic related subgroups within the larger network, yet the actual production of OEP happens on an individual or institutional basis; the same holds for FutureLearn. All cases reported a large amount of experience and expertise within the OEPs. The extent to which shared practice consists of permanent social activities, even beyond the boundaries of institution or domain, appears to be related to the age of the group. For example the ETUG community, part of the BCcampus initiative, knows a history of over 20 years and shows a strong core group of people meeting each other both inside and outside community gatherings.

OERu respondents, being geographically dispersed around the globe, reported that a shared experience takes time to develop and, at this stage in the OERu's history, the concept of shared practice is more evident in the member institutions, where colleagues have a longer shared history, than in the network as a whole. This aspect differentiates the dimensions practice and domain; because in this case the domain is shared on network level and shared practice is mostly located in the subgroups.

For most case studies shared practice happens both online and offline. Online participation is reported to be facilitated by a wide range of available communication and social media tools, such as wikis, forums, mailing lists, and a number of purpose built platforms. These tools are used in diverse ways, from short periods of browsing to 
engagement that is more reflective. OEPs with a focus on the production of open educational resources or MOOCs rather than collaborative production of knowledge reported using fewer tools and mainly wiki-type or online learning environment-type applications. All technologies are reported to be easily available to participants, provided they have Internet access. Regarding usability and technology support, the interview respondents stated that most tools were easy to use. Whenever problems arose, most groups relied on their institutions with helpdesk or in-house technicians.

\section{C) Collective Identity}

The dimension identity is composed of indicators related to the extent to which the network shows strong ties, a shared experience and identity, and members are able to articulate relationships with others that involve a distribution of functions or roles.

A strongshared identity, related to the domain and goal of the community, can be found in the OERu initiative. The shared identity refers to the philanthropic values and purpose of widening access to education using OEP. All OERu participants reported feeling that they belonged to the network and had a sense of ownership.

Within BCcampus and Re:Source there is no evidence of a shared identity on the network level. Yet, subgroups within the networks with an extensive history, sometimes extending long before the beginnings of the initiative, were reported to have a more profound shared identity. BCcampus, for example, counts on existing communities of practice to drive the learning that is necessary for use: "When we started, long before the start of BCcampus, everyone had a purpose coming from their own institutions; as time went on we developed stronger connections to the ETUG-community."

Respondents all reported their networks as being open, trusting, and collaborative. Participants saw each other as equals, although the case studies show that instrumental networks such as UvaMOOC and Digischool consist of a core group of technical and coordinating staff, showing a co-creating relationship, and a large group of (mostly) non-sharing consumers. UvAMOOC participants shared the feeling that they were collaborating in an interesting experiment in the first massive open online course. The feeling of having a shared identity differs strongly per case study, along the lines of the dimensions domain and practice: Case studies that are support driven showed a stronger collective identity compared to the more instrumental cases.

\section{D) Organization}

All examined OEPs are complex organizations comprising diverse forms of networks, (older) communities and smaller teams. All are (inter)national initiatives, with support from regional or national politics, except for UvAMOOC, where all participating members were located in one institution. Despite the national or regional origin of the case studies, the institutional teams and communities often deal with local issues: specific aspects of education or particular applications of technology. This is true even in 
cases where global issues are at the heart of initiatives, such as OERu and BCcampus, where improving access to education is central, since each of the partner institutions also has its own local needs and audience to address.

Coordinators and staff members often state that they do not have enough time or resources to give the OEPs the attention required. The longer-standing networks have a more defined organization compared to newer networks. Networks focused on creating and sharing new knowledge have a collaborative atmosphere, often extending beyond the community itself.

ETUG (BCcampus) is a social bunch that get together for instance to make music. This strengthens the community. During informal meetings, experiences are shared. There is a lot of work virtually, so the face to face events add to the community feeling and shared history.

Because of what was described as a less active audience, instrumental cases such as Digischool are often experienced as only partly collaborative.

There is not much co-creation [in Digischool]. You can show that you have made it together with someone, but in my experience, this does not happen much. ... When it's made, it is made. Maybe people are open to more cocreation, but it doesn't happen (yet).

Most of the cases featured a central actor that either set things in motion or kept the energy in the community high (e.g., by active recruitment of contributors or active inviting of contributions). Within OERu respondents doubted the sustainability of the network without their central figure "[who] does a brilliant job of keeping people in the loop, of engaging with new partners, of getting contacts together", and worried that "without a central unit, institutions could wander off in various directions". On the other hand, the OERu coordinator himself claimed, "There are natural leaders who emerge [within the partner institutions] and that's who we work with" (interviews with OERu respondents cited in Witthaus, 2013a, b, and c).

Both contributions by media creators (technicians) and content creators (teachers or other) were key for the activity level of the community. The importance of a central actor specifically holds for initiatives focused on sharing and creating knowledge. In terms of interactional repertoire, all OEPs showed a mixture of types of communication and behaviour, while communities centered on resource use showed more unidirectional interactions. 


\section{Learning as a Result of the Social Configuration}

Our results show mixed forms of social configurations within the OEP case studies, providing further evidence that team, community, and network aspects are all part of the social structure of a given group (Wenger, Trayner, \& De Laat, 2011; Doornbos \& De Laat, 2012; Schreurs, et al., 2014). Most OEPs involve complex organizations with a diversity of networks, communities, and smaller teams. The results second our hypothesis that different social configurations support a variety of social learning activities (Vrieling, Van den Beemt, \& De Laat, in press), such as co-creation, sharing knowledge, or sustaining networks of relevant others. This result correlates with Dron and Anderson's (2014) finding that few of the categories are absolute in any given group of people.

The teams are situated within individual institutions and focus mostly on a shared practice: Both learning about the production of OEPs and their creation happens mostly within the teams. Despite the fact that team members have been assigned specific roles or functions to perform' and are more hierarchically organized in our case studies, they do have a shared identity (Salas, Dickinson, Converse, \& Tannenbaum, 1992), which resonates with items in the community indicator framework (Galley, et al., 2012). Within institutional teams, we see that members are participating in open networks of practice going beyond the borders of their institutions. We distinguished two types of open networks of practice. Within the support-driven networks practitioners cross their institutional boundaries to search for and share knowledge and expertise about the use of OEPs. The support-driven OEPs report more symbolic learning outcomes (Van den Beemt, Ketelaar, Diepstraten, \& De Laat, 2014), such as mutual understanding, value in work, and inspiration. For example, within OERu, the shared identity leads to powerful social learning:

Oh this is the most rewarding experience of my entire career. It's a return to the core values of education and to share knowledge freely. At the heart of every educator is this passion to share knowledge; it's [given me] the ability to share this passion. (cited in Witthaus, 2013a)

The instrumental cases were often still looking for shared values, such as in the case of Re:Source: "people are going to have to be exposed to the benefits of sharing, the idea that there is more to be gained by sharing then there is to lose."

When participants of the instrumental cases identified problems related to the intensity with which members participated or noted that participation of certain members was not sustained, this seemed to be at least partly related to a lack of shared identity, where values of the OEP were not (yet) in line with the concerns of other constituting members. Sometimes the innovative drive of the core group and intrinsic motivation found in many other participants was not or could not be shared by all network members. 
Learning that happened within the long-lasting communities seemed the most profound. Members of a community are informally bound by what they do together and by what they have learned through their mutual engagement in these activities (Wenger, 1998). Participants in our case studies reported a strong identity around a common agenda or area for learning. In this way, shared learning and interest of the members, together with a shared social and historical context, keep the community together (Galley, et al., 2012).

There is a lot of work virtually [in BCcampus], so the face to face events add to the community feeling and shared history...[also] for the Open Textbook Initiative, we are beginning to see this. So, we organize a book sprint, an intense event that leads in 4 days to a textbook. This should lead to shared ownership.

We see not only different social learning activities, but also different technologies used within the different social configurations. Within the support-driven networks of open practices, people use mostly one-to-one e-mails or group mailing lists to learn from each other. Within the instrumental networks participants often use shared content management systems to publish their OEPs, but use these individually. The community type networks use a wide range of social media to stay up-to-date with each other and email is used to leverage the expertise of community members, in addition to regular face-to-face meetings.

The findings of the different learning activities within the different social configurations are well demonstrated within the OERu interviews with the coordinator and an institutional member: The institutional member reported reading the discussions that come in through the institutional members' mailing list. He reflects on what is being said, contributes his own ideas via the mailing list, and implements the ideas within his own institution by discussing the ideas with colleagues. Within institutional teams, most learning still takes place offline, through shared practices within their own institution. For example, the OERu institutional member who was interviewed said that the actual deep learning happens within his own institution:

I mean sure there's lots of reflections within the network, but most of those reflections tend to be offline. There's a lot of offline reflection between partners sharing their experiences and helping to inform the process.... [O]ne of the biggest challenges we face in the OER movement at the moment, is crossing the chasm ... from sharing to learn, to learning to share. (cited in Witthaus, 2013b) 


\section{Conclusion}

Our study is based on six different cases that share commitment to OEPs. In order to present truly generalizable results, more data is needed. However, our findings resonate with the experiences of practitioners and can thus provide other practitioners with starting points for initiating and developing OEPs.

The analysis of the social configuration of the six OEPs investigated provided evidence that within one initiative, different social configurations can be embedded (institutional teams, open networks of practice, and a strong community) with different roles, goals, and learning platforms.

Through the investigation of these social configurations, our analysis contributed to an understanding of how social learning activities are taking place. Although members do learn about the practicalities of using OEPs within institutional teams, the participation in open networks of practice does give access to the needed external expertise. Professionals increasingly see participation in open practices as a requirement for professional learning. These open networks of practice are dispersed across geographical and organizational boundaries, are informal and self-directed by nature, and disentangled from hierarchy. Open networks of practice have the potential to offer professionals a more dynamic and more useful 'platform' than CoPs for staying abreast in a rapidly changing profession. However, it is the long-lasting sub-communities and a strong coordinator that provide the drive to enable knowledge that could sustain and empower the knowledge sharing within open networks of practice. Interestingly, there is always some element of the practice geared to continual adaptation and change. Within these sub-communities there are clear forms of collaborative knowledge building, mediated by a variety of technological tools, which might be adapted to newly arising needs. This implies that it is wise, when attempting to build sustainable OEPs, to build on existing, long-standing communities, as this is likely to lend sustainability to the initiative.

In the cases involving instrumental networks, it was mostly suggested that individual motivation was central to active participation, at the same time showing an (overarching) institutional commitment. A typical example would be where specific project funding has been obtained for the development of resources. In these cases, central coordinators may continue to play an important role in sustainability.

In addition, working towards (the maintenance of) a shared identity will help in the creation of sustainable OEPs. Our investigation of this dimension seems to suggest that cases reporting a shared identity had a common view of the value of learning and were aiming to engage in and support knowledge co-creation; their aim was not in the first place instrumental.

Experiencing being part of a community with a shared practice and identity might necessitate the sporadic organization of face-to-face encounters. Co-production seems 
easier to achieve by institutional teams and the constitution of open, trusting, and collaborative relations is still a challenge in totally mediated environments.

\section{Discussion}

This study shows that social learning is complex and dynamic, and relies on supporting structures whether they are based on learning in teams, open networks of practice, or communities. Although the configuration includes different practices and interactional repertoires, learning activities take place at all levels but in different forms and at different levels of intensity (Schreurs, et al., 2014).

The applied framework helps us to further understand how to possibly connect social learning at various levels of scale (Hoppe \& Suthers, 2014). The empirical findings reported in this study show evidence that within an OEP initiative there are multiple forms of participation possible at various levels (and at the same time). For some people it is enough to 'dip in and out' and see the OEP as a potential networking environment and treat it as a source of knowledge and potential learning ties. Occasionally one might take a keen interest in a particular topic or aspect and join a smaller group, that is, a 'team', to help solve a certain issue at hand. Or people might feel that this OEP community provides a kind of home-base and treat it as a community that also provides networking opportunities and the ability to start up temporary sub-groups or teams for particular tasks. The study shows therefore that OEPs facilitate networking, where openness allows the opportunity to meet and participate (a construct perhaps similar to the notion of legitimate peripheral participation (Lave \& Wenger, 1991), but one does not necessarily need to become a core member. This networking layer' is likely to be connected with one (or more sub-) communities dedicated to developing a sense of belonging and maintaining long lasting productive relationships stewarding a shared domain. At a lower level of granularity within the OEP we have seen that teams or taskforces can emerge to solve an immediate problem. Participation within these teams can be drawn from the community or network level. This structure seems to align with the theoretical framework developed by Dron and Anderson (2014) where they identify nets, sets, and groups. They also recognize the fact that these social forms overlap and/ or blend, but the extent to which they are connected at various levels is an issue for further research. The notions of (dynamic) nested forms of social configuring was also found in a study by Doornbos and De Laat (2012) where within an open network of practice on teacher professional development, there was a similar dynamic and mixture of social configurations. In their study they found that the network even took on external requests based on their recognition and status as experts in their field and applied a team-based structure to deliver as well as share their findings within their open network of practice promoting therefore a form of collective intelligence (Dron \& Anderson, 2014). The extent to which the open networks of practice in the current study show evidence and how this contributes to innovation and learning is a topic for further research. Dron and Anderson (2014) argue for example that safety is an important 
factor to stimulate social learning. Especially in sets anonymity could create a safe atmosphere for participants. This could be the case for teachers who use online platforms such as the Dutch initiative Wikiwijs intended at sharing educational materials, as in a recent study teachers claim to be reluctant to use this platform because they are afraid of being judged by colleagues. The importance of safety is also found in other studies (cf. Van den Beemt, et al., 2014).

A final issue worth mentioning in the discussion is how these theoretical and practical frameworks can help to promote and assess learning and the value that these open practices produce. Now that professionals join these open practices outside the organizations they work for (and meet and collaborate with self employed professionals) it will be even more difficult to manage and recognize valuable knowledge or skills within an organization. Participation in open practices challenges the more traditional forms of career path development, intellectual property, and organizational human resource management systems. At the same time, it provides new opportunities for those organizations and individuals that are open to exploring the benefits of collaboration and co-construction of knowledge beyond institutional boundaries.

\section{Acknowledgements}

This study is conducted within the frame of the POERUP project, funded by the lifelong learning program of the European Commission (POERUP, 2013). The POERUP project aims to enable the development of policies to stimulate the uptake of open educational resources. Within the POERUP project, partners from the Open University of the Netherlands, Sero Consulting and the University of Leicester, and the University of Athabasca collaborated to gather all the data with help from the OEP initiatives under investigation. 


\section{References}

Admiraal, W., Lockhorst, D., \& van der Pol, J . (2012). An expert study of a descriptive model of teacher communities. Learning Environments Research, 15(3), 345361.

Bottrup, P. (2006). Learning in a network: A "third way" between school learning and workplace learning?. J ournal of Workplace Learning, 17(8), 508-520.

Boud, D., \& Hager, P. (2012). Re-thinking continuing professional development through changing metaphors and location in professional practices. Studies in Continuing Education, 34(1), 17-30.

Brown, J . S., \& Duguid, P. (2001) Knowledge and organization: A social-practice perspective. Organization Science, 12(2), 198 - 213.

Büchel, B., \& Raub, S. (2002). Building knowledge creating value networks. European Management J ournal, 20(6), 586-596.

De Laat, M. F., Schreurs, B., \&Nijland, F. (2014) Communities of practice: Balancing openness, networking and value creation. In R. F. Poell, T. S. Rocco \& G. L. Roth (Eds.), The Routledge companion to human resource development. London: Routledge.

Dechant, K., Marsick, V. J ., \& Kasl, E. (1993). Towards a model of team learning. Studies in Continuing Education, 15(1), 1-14.

Doornbos, A., \& de Laat, M. (2012). De waarde van communities of practice in het groene onderwijs. [The value of communities of practice in green education] (Report). Ede: GKC.

Dron, J ., \&Anderson, T. (2007). Collectives, networks, and groups in social software for elearning. World Conference on E-Learning in Corporate, Government, Healthcare, and Higher Education (ELEARN) 2007, Quebec City, Quebec, Canada.

Dron, J ., \& Anderson, T. (2014). Agoraphobia and the modern learner. J ournal of Interactive Media in Education. Retrieved from http:// wwwjime.open.ac.uk/jime/article/view/2014-03

Fetter, S., Berlanga, A. J ., \& Sloep, P. B. (2011). Peer-support and open educational resources. Collaborative Learning, 2.

FutureLearn. (2013). Futurelearn launches. Retrieved from http:/ / futurelearn.com/ feature/futurelearn-launches/ 
Galley, R., Conole, G., \&Alevizou, P. (2012). Community indicators: A framework for observing and supporting community activity on Cloudworks. Interactive Learning Environments. DOI: 10.1080/ 10494820.2012.680965

Glaser, B. G., \& Strauss, A. L. (2009). The discovery of grounded theory: Strategies for qualitative research. Transaction Publishers.

Hoppe, H. U., \& Suthers, D. D. (2014, March). Computational approaches to connecting levels of analysis in networked learning communities. In Proceedings of the Fourth International Conference on Learning Analytics And Knowledge (pp. 285-286). ACM.

Knapp, R. (2010). Collective (team) learning process models: A conceptual review. Human Resource Development Review, 9(3), 285-299.

Lane, A. (2008). Reflections on sustaining open educational resources: An institutional case study. eLearning Papers. Retrieved August, 31, 2010 from http:// www.elearningpapers.eu/index.php?page $=$ doc\&doc id $=12405 \& d o c l n g=$ $\underline{6 \& v o l=10}$

Lave, J ., \&Wenger, E. (1991). Situated learning: Legitimate peripheral participation. Cambridge University Press.

Lohman, M. C. (2006). Factors influencing teachers' engagement in informal learning activities. J ournal of Workplace Learning, 18(3), 141-156.

POERUP. (2013). Policies for OER uptake. Progress report. Retrieved from http:// poerup.referata.com/w/images/2011_4021 PR_POERUP_pub.pdf

Pugh, K., \& Prusak, L. (2013). Designing effective knowledge networks. MIT Sloan Review. Retrieved from http:// sloanreview.mit.edu/article/designing-effectiveknowledge-networks/

Salas, E., Dickinson, T. L., Converse, S. A., \&Tannenbaum, S. I. (1992). Toward an understanding of team performance and training. In R. W. Swezey \& E. Salas (Eds.), Teams: Their training and performance (pp.3-29). NJ : Ablex.

Schreurs, B., Van den Beemt, A., Prinsen, F., De Laat, M., Witthaus, G., Conole, G. (2014). Investigating the social configuration of a community to understand how networked learning activities take place: The OERu case study. Paper presented at the 2014 Networked Learning Conference, Edinburgh, UK.

Van den Beemt, A., Ketelaar, E., Diepstraten, I., \& De Laat, M. (2014). Reciprocity in knowledge networks. Paper presented at the 2014 Networked Learning Conference, Edinburgh, UK. 
Vrieling, E., Van den Beemt, A., \& De Laat, M. (in press). What's in a name: Dimensions of social learning in teacher groups. Teachers and Teaching: theory and practice.

Wenger, E. (1998). Communities of practice: Learning, meaning, and identity. Cambridge University Press.

Wenger, E., Trayner, B., \& de Laat, M. (2011). Promoting and assessing value creation in communities and networks: A conceptual framework. The Netherlands: Ruud de Moor Centrum.

Witthaus, G. (2013a). The OERu is smart philanthropy: Interview with Wayne Mackintosh. ILI Blog August 14th. Retrieved from http:// beyonddistance.wordpress.com/ 2013/08/ 14/ the-oeru-is-smartphilanthropy-interview-with-wayne-mackintosh/

Witthaus, G. (2013b). In the OERu, education is something that grows as it shares: An interview with Haydn Blackey. ILI Blog August 15th. Retrieved from http:// beyonddistance.wordpress.com/2013/08/ 15/in-the-oeru-education-issomething-that-grows-as-it-shares-an-interview-with-haydn-blackey/

Witthaus, G. (2013c). As I was contributing, I was learning: An interview with Bernard Nkuyubwatsi. ILI Blog. Retrieved from http:// beyonddistance.wordpress.com/2013/ 08/16/as-i-was-contributing-iwas-learning-an-interview-with-bernard-nkuyubwatsi/

\section{Athabasca University $\mathbf{Z}$}

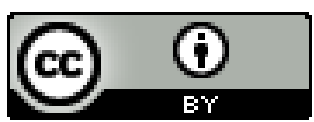

